\title{
PENGARUH KREATIVITAS DAN GAYA BELAJAR PADA MATA PELAJARAN MATEMATIKA TERHADAP HASIL BELAJAR MATEMATIKA SISWA
}

\author{
1) Mila Padliah, ${ }^{2)}$ Heni Pujiastuti \\ Universitas Sultan Ageng Tirtayasa \\ 1)padliahmila.614@gmail.com, ${ }^{2)}$ henipujiastuti@untirta.ac.id
}

\section{Received: \\ $26 / 04 / 2020$ \\ Accepted : \\ $22 / 06 / 2020$ \\ Published: \\ 10/07/2020}

\begin{abstract}
This research is motivated by the problems that exist in the process of learning mathematics in schools, namely among the difficulties faced by students in solving mathematical problems with a new way of solving, which requires creativity and use of learning styles to absorb a learning. The research was conducted with the aim to determine the effect of creativity and learning styles on mathematics subjects on learning outcomes in mathematics. This type of research is a correlational research with a quantitative approach. The population used in the study were 12th grade students of MA Private Plus Darul Huda Cikoneng, while the sample used to conduct research was 12th grade science students. Data in this study were collected using a questionnaire instrument and documentation of learning outcomes. Data analysis in this study was conducted using a multiple regression analysis correlation test, to determine the effect of creativity and learning styles on mathematics subjects on mathematics learning outcomes. The results of data analysis using the multiple regression analysis correlation test showed that creativity and learning styles in mathematics subjects had a significant effect on learning outcomes in mathematics.
\end{abstract}

Keywords: Creativity, Learning Styles, Learning Outcomes, Correlations

\begin{abstract}
Abstrak
Penelitian ini dilatar belakangi oleh adanya permasalahan-permasalahan yang terdapat pada proses pembelajaran matematika di sekolah, yaitu di antaranya kesulitan yang dihadapi siswa dalam menyelesaikan permasalahan matematika dengan cara penyelesaian baru, yang mana hal ini membutuhkan adanya kreativitas dan penggunaan gaya belajar dalam menyerap suatu pembelajaran. Adapun penelitian ini dilakukan dengan tujuan untuk mengetahui pengaruh dari kreativitas dan gaya belajar pada mata pelajaran matematika terhadap hasil belajar matematika. Jenis penelitian yang digunakan adalah penelitian korelasional dengan pendekatan kuantitatif. Populasi yang digunakan pada penelitian adalah siswa kelas 12 MA Swasta Plus Darul Huda Cikoneng, sementara itu sampel yang digunakan untuk melakukan penelitian adalah siswa kelas 12 IPA 1. Data pada penelitian ini dikumpulkan dengan menggunakan instrumen angket dan teknik dokumentasi hasil belajar. Analisis data pada penelitian ini dilakukan dengan menggunakan uji korelasi analisis regresi ganda, untuk mengetahui pengaruh kreativitas dan gaya belajar pada mata pelajaran matematika terhadap hasil belajar matematika. Hasil analisis data dengan menggunakan uji korelasi analisis regresi ganda menunjukan bahwa kreativitas dan gaya belajar pada mata pelajaran matematika memiliki pengaruh yang signifikan terhadap hasil belajar matematika.
\end{abstract}

Kata Kunci: Kreativitas, Gaya Belajar, Hasil Belajar, Korelasi

\section{Pendahuluan}

Matematika memiliki peranan yang penting dalam ilmu Pendidikan, hal ini terlihat dari adanya mata pelajaran Matematika di setiap jenjang sekolah, baik tingkat sekolah dasar, menengah maupun perguruan tinggi. Matematika juga merupakan ilmu pengetahuan yang bermanfaat bagi perkembangan ilmu lainnya baik ilmu eksakta seperti Fisika dan Kimia, maupun ilmu sosial (Hartati, 2015). Melihat dari fakta tersebut, maka siswa diharuskan untuk mempelajari matematika dengan sungguh- 
sungguh agar dapat menghasilkan hasil belajar matematika yang baik bahkan memuaskan.

Pada kenyataannya masih banyak siswa yang mengalami hambatan dalam mempelajari matematika, hal ini dapat dilihat dari hasil belajar matematika siswa yang rendah dan tidak memuaskan. Siswa yang mengalami hambatan dalam pembelajaran tersebut, dapat digolongkan ke dalam siswa yang mengalami kesulitan belajar. Kesulitan belajar merupakan ketidakmampuan siswa dalam menguasai fakta, konsep, prinsip, dan keterampilan (Waskitoningtyas, 2016).

Kesulitan belajar yang terjadi pada siswa dapat disebabkan oleh faktor internal dan eksternal. Faktor internal adalah faktor yang berasal dari dalam diri siswa, misalnya kesehatan, bakat, minat, motivas, intelegensi dan sebagainya, sedangkan faktor eksternal adalah faktor-faktor yang berasal dari luar diri siswa misalnya dari lingkungan sekolah, lingkungan keluarga dan lingkungan masyarakat (Jamal, 2014).

Berdasarkan penelitian yang telah dilakukan sebelumnya, menyatakan bahwa sebagian siswa masih mengalami kesulitan dalam menyelesaikan permasalahan matematika yang diberikan guru. Hal ini terlihat dari hasil Programme for International Student Assessment (PISA) tahun 2018, yang mana skor matematika siswa Indonesia masih di bawah rata-rata yaitu sebesar 379, sedangkan skor rata-rata internasional adalah sebesar 489 sehingga menempatkan Indonesia pada posisi ke 72 dari 78 negara yang berpartisipasi dalam PISA (OECD, 2019).

Siswa dalam menyelesaiakan soal matematika cenderung mengikuti cara seperti apa yang dicontohkan oleh guru, ketika permasalahan yang dihadapinya sedikit berbeda penyajian maka mereka akan merasa kesulitan untuk menyelesaikannya (Budiarti \& Jabar, 2016). Berdasarkan fakta tersebut maka diperlukan kemampuan berkreativitas agar siswa dapat memilih dan menerapkan cara atau metode yang tepat guna menyelesaikan permasalahan yang dihadapinya dengan benar.

Kemampuan berkreativitas yang dimiliki siswa berbeda-beda, hal ini karena masing-masing siswa memiliki cara yang berbeda dalam menyerap, mengatur dan mengolah bahan informasi yang diberikan dalam pembelajaran. Cara yang digunakan oleh siswa dalam menyerap, mengatur dan mengolah bahan informasi yang diberikan dalam pembelajaran adalah gaya belajar mereka masing-masing (Karim, 2015).

Gaya belajar adalah gaya yang dimiliki siswa dalam proses pembelajaran untuk menyerap suatu materi pembelajaran. Setiap siswa mempunyai gaya belajar yang berbeda-beda (Salsabila, 2019). Ada siswa yang lebih senang membaca, berdiskusi dan ada juga yang senang praktik langsung (Marwanto, 2020). Berdasarkan cara belajar yang berbeda ini, maka dari itu setiap orang memiliki cara belajar efektif yang berbeda untuk satu sama lain. Terdapat tiga jenis gaya belajar yang paling utama yaitu visual, auditory (auditorial), dan kinaesthetic (kinestetik) (Pourhosein Gilakjani, 2011).

Berdasarkan preferensi sensori, pelajar visual belajar melalui sesuatu yang mereka lihat, auditorial belajar dengan cara mendengar, dan kinestetik belajar dengan gerak, bekerja, dan menyentuh. Setiap siswa memiliki ketiga gaya belajar tersebut, hanya saja biasanya satu gaya lebih mendominasi (Bire, Geradus, \& Bire, 2014).

Hasil belajar adalah kemampuan yang diperoleh siswa meliputi kemampuan kognitif, afektif, dan psikomotorik (Nawi, 2012). Hasil belajar adalah pencapaian siswa 
selama proses pembelajaran yang ditunjukkan dalam bentuk nilai. Hasil belajar merupakan hasil akhir dari serangkaian pembelajaran yang dilakukan oleh siswa (Sutama \& Anggitasari, 2019).

Rendahnya hasil belajar matematika siswa dapat disebabkan oleh beberapa faktor meliputi faktor dari siswa itu sendiri, guru, metode pembelajaran maupun lingkungan (Darkasyi, Johar, \& Ahmad, 2014). Salah satu faktor dari siswa yang menyebabkan rendahnya hasil belajar yakni karena kurangya kreativitas yang dilakukan oleh siswa dalam menyerap, mengatur dan mengolah informasi dalam pembelajaran yang diberikan oleh guru, hal ini disebabakan karena kurang tepatnya pemilihan gaya belajar oleh siswa. Berdasarkan uraian-uraian tersebut, maka rumusan masalah pada penelitian ini yaitu adakah pengaruh kreativitas dan gaya belajar pada mata pelajaran matematika terhadap hasil belajar matematika.

\section{Metode Penelitian}

Penelitian ini merupakan jenis penelitian korelasional dengan menggunakan pendekatan kuantitatif. Populasi yang digunakan pada penelitian adalah siswa kelas 12 MA Swasta Plus Darul Huda Cikoneng, sementara itu sampel yang digunakan untuk melakukan penelitian adalah siswa kelas 12 IPA 1. Teknik pengumpulan data yang digunakan dalam penelitian ini adalah angket dan dokumentasi nilai hasil UAS (Ujian Akhir Semester) mata pelajaran matematika pada semester gasal.

Instrumen peneltian yang digunakan berupa angket kreativitas, angket gaya belajar, serta dokumentasi hasil UAS (Ujian Akhir Semester) mata pelajaran matematika siswa pada semester gasal. Angket kreativitas matematika terdiri dari 24 butir pernyataan yang bertujuan untuk mengetahui tingkat kreativitas siswa pada mata pelajaran matematika. Angket Gaya Belajar terdiri dari 30 butir pernyataan untuk mengukur 3 aspek gaya belajar yaitu Visual, auditorial, dan kinestetik. Sedangkan dokumentasi nilai hasil UAS matematika siswa pada semester gasal merupakan metode untuk mengumpulkan hasil belajar matematika masing-masing siswa.

Teknik analisis data yang digunakan dalam penelitian ini diantaranya yaitu pertama melakukan analisis deskriptif, melakukan pengujian prasyarat analisis regresi yang meliputi uji normalitas uji linearitas, dan uji multikolinieritas dan kemudian dilakukan analisis atau pengujian korelasi dengan menggunakan analisis regresi linear berganda, yang mana kegiatan pengujian atau analisis terhadap data yang diperoleh tersebut dilakukan dengan menggunakan bantuan program SPSS.

\section{Hasil dan Pembahasan}

Berdasarkan penelitian yang telah dilakukan, pada bagian hasil dan pembahasan ini akan dilakukan pemaparan analisis deskriptif, pengujian prasyarat uji korelasi yang meliputi uji normalitas, uji linearitas, dan uji multikolinearitas, serta pemaparan uji korelasi dengan menggunakan pengujian analisis regresi ganda dengan menggunakan bantuan program SPSS.

Deskripsi data hasil angket untuk tingkat kreativitas dan gaya belajar siswa terdapat pada Tabel 1 dan Tabel 2. 
Tabel 1. Deskripsi Data Kreativitas

\begin{tabular}{cl}
\hline \hline Deskripsi Data & Nilai \\
\hline Banyaknya Siswa & 21 \\
Rata-Rata & 74,43 \\
Skor Maksimum & 84 \\
Skor Minimum & 59
\end{tabular}

Berdasarkan Tabel 1 tersebut dapat diketahui bahwa banyaknya responden adalah 21, dari 21 responden tersebut nilai maksimum dan minimum yang diperoleh secara berturut-turut adalah 84 dan 59. Sedangkan Nilai rata-rata yang diperoleh dari data kreativitas adalah sebesar 74,43. Kemudian berdasarkan Tabel 2 dapat kita ketahui bahwa nilai maksimum dan minimumnya secara berturut-turut adalah 101 dan 61, sedangkan nilai rata-ratanya adalah sebesar 87,43.

Tabel 2. Deskripsi Data Gaya Belajar

\begin{tabular}{ll}
\hline \hline Deskripsi Data & Nilai \\
\hline Banyaknya Siswa & 21 \\
Rata-Rata & 87,43 \\
Skor Maksimum & 101 \\
Skor Minimum & 61 \\
\hline
\end{tabular}

Tahap selanjutnya yaitu melakukan pengujian prasyarat uji korelasi yang meliputi uji normalitas, uji linearitas, dan uji multikolinearitas. Adapun hasil dari pengujian tersebut dapat dilihat pada Tabel 3 dan Tabel 4.

Tabel 3 Uji Normalitas dan Uji Linearitas

\begin{tabular}{|c|c|c|c|}
\hline Jenis Uji & Keterangan & Nilai $p$ & Hasil \\
\hline & One-Sample & & \\
\hline Uji Normalitas & Kolmogorov- & 0.200 & Normal \\
\hline & Smirnov Test & & \\
\hline Uji Linearitas & $\begin{array}{c}\text { Deviation from } \\
\text { Linearity }\end{array}$ & 0.351 & Linear \\
\hline
\end{tabular}

Berdasarkan hasil pengujian tersebut, maka dengan menggunakan taraf signifikansi sebesar $\alpha=0,05$ dapat diperoleh bahwa uji normalitas dan uji linearitas untuk data tersebut telah terpenuhi dan berdasarkan nilai VIF pada Tabel 4 tidak terjadi masalah multikolinieritas, hal ini karena nilai VIF $=1,023$ yang berada di sekitar angka 1 dan nilai toleransi sebesar 0,978 mendekati 1 sehingga tahapan pengujian yang selanjutnya dapat dilakukan.

Tabel 4. Uji Multikolinearitas

\begin{tabular}{clcl}
\hline \hline Variabel & Tolerance & VIF & Keterangan \\
\hline Gaya Belajar & 0,978 & 1,023 & Tidak terjadi masalah \\
Kreativitas & 0,978 & 1,023 & multikolinearitas \\
\hline
\end{tabular}


Adapun pengujian yang selanjutya yaitu pengujian korelasi antar variabel untuk mengetahui pengaruh antara kreativitas (X1), gaya belajar (X2), dan hasil belajar (Y) dengan menggunakan uji analisis regresi linier ganda. Hasil pengujian korelasi tersebut dapat dilihat pada Tabel 5 .

Tabel 5. Uji Korelasi Ganda

\begin{tabular}{cccccc}
\hline \hline & $\mathrm{R}$ & $\mathrm{R} 2$ & Fhitung & Ftabel & sig. F Change \\
\hline $\begin{array}{c}\text { Model } \\
\text { Summary }\end{array}$ & 0,575 & 0,331 & 4,449 & 3,52 & 0,027 \\
\hline
\end{tabular}

Berdasarkan Tabel 5 tersebut dapat diketahui bahwa nilai probabilitas (sig. F Change) adalah sebesar 0,027, hal ini berarti nilai sig. F Change $<0,05$. Sedangkan nilai Fhitung adalah sebesar 4,449 yang berarti Fhitung $>$ Ftabel yang bernilai 3,52, sehingga berdasarkan hasil uji korelasi ganda tersebut dapat diketahui bahwa kreativitas (X1) dan gaya belajar (X2) memiliki pengaruh yang signifikan terhadap hasil belajar siswa (Y).

Dengan demikian apabila siswa terpacu untuk menciptakan kemapuan kreativitasnya, maka siswa telah mampu menyerap dan memahami pembelajaran yang diberikan oleh guru dengan menggunakan gaya belajar yang tepat dan sesuai. Sehingga kreativitas dan gaya belajar tersebut, dapat menciptakan hasil belajar siswa yang optimal.

Sesuai dengan penelitian yang telah dilakukan oleh (Sagitasari, 2010), yang menyatakan bahwa dengan menyesuaikan gaya belajar yang tepat siswa dapat meningkatkan prestasi belajar matematikanya. Hal ini sejalan dengan teori yang menyebutkan bahwa konsep belajar atau gaya belajar individu sebagai satu usaha yang dilakukan individu untuk belajar, erat kaitannya dengan hasil belajar individu untuk belajar (Istiqomah, 2017).

Hal ini didukung pula oleh pendapat yang menyebutkan bahwa mengetahui gaya belajar yang berbeda telah membantu para siswa, dengan demikian akan memberi persepsi yang positif bagi siswa tentang cara guru mengajar (DePorter \& Hernacki, 2000). Sejalan dengan hal tersebut, maka guru seharusnya dapat memahami dan memfasilitasi siswa untuk dapat menerima apa yang diberikan oleh guru sesuai dengan gaya belajarnya, sehingga siswa dapat menggali kreativitasnya dalam proses pembelajaran. Hal ini karena kreativitas yang terdapat dalam suatu individu dapat mendorongnya untuk memecahkan suatu persoalan dengan cara berpikir yang akan digunakannya (Istiqomah, 2017).

\section{Kesimpulan}

Berdasarkan hasil analisis data yang telah dilakukan sebelumnya, maka dapat ditarik kesimpulan bahwa kreativitas dan gaya belajar pada mata pelajaran matematika dapat berpengaruh terhadap hasil belajar matematika. Hal ini berdasarkan pada hasil uji korelasi ganda dimana nilai signifikan yang diperoleh dari hasil pengujian menggunakan SPSS bernilai 0,027 yang mana hal ini berarti nilai signifikan $<0,05$, sehingga masing-masing variabel uji tersebut memiliki hubungan yang sangat signifikan atau memiliki pengaruh yang cukup besar. Hal ini berarti bahwa apabila siswa terpacu 
untuk menciptakan kemapuan kreativitasnya dengan menggunakan gaya belajar yang tepat dan sesuai, maka hasil belajar yang didapatkannya akan optimal. Dengan demikian, dapat disimpulkan bahwa kreativitas dan gaya belajar pada mata pelajaran matematika sangat berpengaruh terhadap hasil belajar matematika.

\section{Pustaka}

Bire, A. L., Geradus, U., \& Bire, J. (2014). Pengaruh Gaya Belajar Visual, Auditorial, Dan Kinestetik Terhadap Prestasi Belajar Siswa. Jurnal Kependidikan, 44(2). https://doi.org/10.21831/jk.v44i2.5307

Budiarti, I., \& Jabar, A. (2016). Pengaruh gaya belajar terhadap hasil belajar matematika siswa kelas VIII SMPN 2 Banjarmasin tahun ajaran 2015/2016. Math Didactic: Jurnal Pendidikan Matematika, 2(3), 142-147. https://doi.org/10.33654/math.v2i3.42

Darkasyi, M., Johar, R., \& Ahmad, A. (2014). Peningkatan Kemampuan Komunikasi Matematis dan Motivasi Siswa dengan Pembelajaran Pendekatan Quantum Learning pada Siswa SMP Negeri 5 Lhokseumawe. Jurnal Didaktik Matematika, $1(1), 21-34$.

DePorter, B., \& Hernacki, M. (2000). Quantum Learning (Revisi). Bandung: Kaifa.

Hartati, L. (2015). Pengaruh Gaya Belajar dan Sikap Siswa pada Pelajaran Matematika terhadap Hasil Belajar Matematika. Formatif: Jurnal Ilmiah Pendidikan MIPA, 3(3), 224-235. https://doi.org/10.30998/formatif.v3i3.128

Istiqomah, M. N. (2017). Pengaruh Gaya Belajar dan Kreativitas Terhadap Prestasi Belajar Siswa Kelas V Sd Se-Gugus Mardisiswa Kecamatan Gumelar Kabupaten Bantumas. Universitas Negeri Semarang. Semarang: Universitas Negeri Semarang.

Jamal, F. (2014). Analisis Kesulitan Belajar Siswa Dalam Mata Pelajaran Matematika Pada Materi Peluang Kelas XI IPA SMA Muhammadiyah Meulaboh Johan Pahlawan. Jurnal MAJU (Jurnal Pendidikan Matematika), 1(1), 18-36. Retrieved from http://www.ejournal.stkipbbm.ac.id/index.php/mtk/article/view/232

Karim, A. (2015). Pengaruh Gaya Belajar dan Sikap Siswa pada Pelajaran Matematika Terhadap Kemampuan Berpikir Kritis Matematika. Formatif: Jurnal Ilmiah Pendidikan MIPA, 4(3), 188-195. https://doi.org/10.30998/formatif.v4i3.154

Marwanto, R. (2020). Peningkatan Hasil Belajar Materi Persamaan Kuadrat Melalui Model Pembelajaran Think Pair Share Berbantuan Komputer Pada Siswa Kelas Ixb Smp Negeri 26 Semarang. Delta: Jurnal Ilmiah Pendidikan Matematika, 8(1), 107. https://doi.org/10.31941/delta.v8i1.970

Nawi, M. (2012). Pengaruh Strategi Pembelajaran dan Kemampuan Penalaran Formal terhadap Hasil Belajar Matematika Siswa Sekolah Menengah Atas (Swasta) AL 
ULUM Medan. Jurnal Tabularasa PPS UNIMED, 9(1), 81-96.

OECD. (2019). PISA 2018 Results: What Student Student Know and Can Do. https://doi.org/10.1787/5f07c754-en

Pourhosein Gilakjani, A. (2011). Visual, Auditory, Kinaesthetic Learning Styles and Their Impacts on English Language Teaching. Journal of Studies in Education, 2(1), 104. https://doi.org/10.5296/jse.v2i1.1007

Sagitasari, D. A. (2010). Hubungan Antara Kreativitas dan Gaya Belajar dengan Prestasi Belajar Matematika Siswa SMP. Universitas Negeri Yogyakarta, (September), 174.

Salsabila, F. (2019). Pengaruh Model Pembelajaran Conceptual Understanding Procedures (CUPs) Berbantuan Media Handout terhadap Kemampuan Pemahaman Konsep ditinjau dari Gaya Belajar di SMK N 3 Pekalongan. Delta: Jurnal Ilmiah Pendidikan Matematika, 7(1), 37. https://doi.org/10.31941/delta.v7i1.922

Sutama, S., \& Anggitasari, B. (2019). Gaya dan Hasil Belajar Matematika pada Siswa SMK. Manajemen Pendidikan, 13(2), 52-61.

Waskitoningtyas, R. S. (2016). Analisis Kesulitan Belajar Matematika Siswa Kelas V Sekolah Dasar Kota Balikpapan Pada Materi Satuan Waktu Tahun Ajaran 2015/2016. JIPM (Jurnal Ilmiah Pendidikan Matematika), 5(1), 24. https://doi.org/10.25273/jipm.v5i1.852 
